\title{
Assessing the Self-reported Level of Knowledge, of Romanian Parents with 4-12 Year Old Children, on Emergency Behavior
}

\author{
Valeria Ionascu ${ }^{1}$, Monica Brinzac ${ }^{2}$, Anamaria Ioana Coci $^{3}$
}

\begin{abstract}
The purpose of this research project is to assess self-reported levels of knowledge of parents with children aging from 4 to 12 by examining parental behavior in emergency situations in Romania. This project is a transversal descriptive study that addresses the objective of the research. This study contains 5 phases: Phase 1: Researching the addressed problem; Phase 2: Creating and developing the main tool, the questionnaire; Phase 3: Applying online the tool to the target group; Phase 4: Collecting online obtained data; Phase 5: Analyzing and evaluating the data obtained after the questionnaire was collected for further interventions. The final conclusion of this study will shed light on parental behavior that directly impacts the well-being of children. The results, furthermore, will be used to establish a link between the level of education and decision-making abilities during emergencies. This shall help parents avoid negative patterns of behavior and maximize the mental and the physical health of children. In other words, the result of the study will provide a baseline for further interventions, proving that family education can benefit not only human life but can also improve monetary income by reducing material damage.
\end{abstract}

Keywords: Disaster and Public Health, Natural disaster management knowledge, Parental education, Child education

\section{Introduction}

The purpose of this research project is to assess the level of knowledge of parents with children between 4-12 years of age, in Romania, regarding parent's behavior in emergency situations.

By emergency situations, I refer to the most common natural disasters that are present in Romania such as: earthquakes, floods and landslides. While several studies have been conducted internationally to assess the level of knowledge about behavior in emergency situations, at the current level in Romania I could not identify to date any publications that would explain the exact purpose of this study and the real scenario. I have chosen parents with 4 to 12 year old children; because children of this age are better able to assimilate and apply the information they receive (Department of Education of California, 2000). Children spend most of their free time in the family according to Varathan P. (Quartz, 2017), thus one can infer that parents present a source of trust for the child. They are being provided by their families with the first education (Families and Early Childhood, 2010), therefore it is important that they are informed on how to behave in emergency

| Second Year through BSc degree in Public Health at the Cluj School of Public Health of Babeș-Bolyai University in Cluj-Napoca, Romania.

| 2 Second Year through BSc degree in Public Health at the Cluj School of Public Health of Babeş-Bolyai University in Cluj-Napoca, Romania. 
situations.

Natural disaster is a catastrophe caused by natural phenomena such as earthquakes, floods or landslides, causing environmental damage, material impair and loss of human life (Collins, 2016). Global catastrophic events have influenced people's lives over the years and have had a significant growth rate, causing global economic losses (Gavriletea, 2017). One of the several studies conducted at international level would be a study in Nepal on students' knowledge of emergency behavior. The results of the study have shown that the level of knowledge is low in all schools in Nepal, even if statistics on natural disasters in Nepal are always thrilling (Tuladhar, 2013).

Romania is a country where natural disasters are commonplace. Having a single seismic center Romania is affected by earthquakes and tremors present in the south and southwest parts of the country, severely affecting one part of the country while the other remains partly affected (Newsroom, 2011).

Romania has been affected by floods, torrents and landslides in the northeastern parts of the country after a heavy rainfall in 2010. Landslides are also common in most regions of the country. According to Ion Tecuci “Approximately 4 percent of Romania's territory is exposed to flooding, affecting over 1 million inhabitants" (Newsroom, 2011).

Because of the limited data on the number of cases that have taken place over the years in Romania, there is a lack of information in this domain. The evaluation process is important in determining an appropriate response to emergency behavior. That is why we need data to assess parents' level of knowledge about their behavior in critical situations.

Emergency situations differ from one to the other; the severity of some may require first aid. Parents being the first source of information for children and having knowledge of emergency behavior can easily share knowledge with their children from an early age. According to the National Biotechnology Information Center, children of preschool age are able to assimilate and practice the basic knowledge in giving first aid (National Biotechnology Information Center, 2011). This knowledge will allow children to cooperate, adapt and cope with any emergency situation until authorities intervene.

It is impossible to prevent or predict how and where a natural catastrophe will occur. But through appropriate training we can protect lives and reduce the damage caused by these disasters (The Japan Times, 2015).

A relevant example is Japan. They regularly hold earthquake drills in schools (Web-Japan, 2007), to learn and practice what to do and how to act in various emergency situations such as earthquakes and floods. By adequate training the mortality rate and material damage can be significantly reduced. Over the years, Japan has been hit constantly by natural disasters that have taken thousands of lives, now Japan is planning appropriate strategies for each region to deal with natural disasters.

Japan is a country with sophisticated earthquake warnings and tsunami, and a public with the necessary knowledge for such events, including the transition to established evacuation areas and a prepared survival bag. That is why Japan is considered to be the most prepared country in case of a natural hazard (Beville, 2011).

A natural catastrophe present in Europe that puts people's lives at risk is the slip of land, with deadly accidents. Over the years, the highest rate has been established in Turkey. (Haque, 2016)

Another global emergency is flood, which can be a major life risk and can cause massive 
environmental damage. A good example would be the European floods of 2016, which affected Europe largely in the western and northeastern regions. There are some studies that have tried to explain the causes of an emergency like this. Studies find that global warming is a cause of the flood river (McGrath, 2017). In my opinion the presence of such a problem requires knowledge of emergency situations, as this problem is also present in Romania.

\section{Methodology}

The study design is a cross-sectional analysis that addresses the objective of the study. This is a study that attempts to describe the current state of an identified variable which acquaints the researcher with the main details and information about a problem that has not been studied before. This project contains 5 phases and was developed over a 12-month period.

Phase 1: Researching the addressed problem;

Phase 2: Creating and developing the main tool, the questionnaire;

Phase 3: Applying online the tool to the target group;

Phase 4: Collecting online obtained data;

Phase 5: Analyzing and evaluating the data obtained after the questionnaire was collected for further interventions;

The sample study consists of parents with 4-12 year old children from Romania, this target population was chosen because children aged between 4-12 years old are able to better assimilate and apply the information received (Department of Education of California, 2000).

The target population was a sample of convenience with 120 respondents (male or female). This study proposes to measure some concepts that could influence the level of knowledge of parents using a questionnaire based on mixed methods analysis:

Concept 1: Socio-demographic variables in terms of age, gender, ethnicity, civil status, residence, level of education, knowledge and knowledge management about natural disasters, if they have ever been through natural disasters, if they took part in courses sharing this knowledge, if they share their knowledge with their children and what are their opinions regarding natural disasters causing physical and psychological traumas;

Concept 2: The relation between the main variables and parents being ready to act in case of a natural disaster occurrence;

Concept 3: The parent's natural disaster level of management knowledge and parent's readiness towards emergency situations as being a predictor of knowledge sharing;

For this study a mixed data collection strategy was used, tracking the following steps:

Step 1: The development of the questionnaire, the information page and the inform consent;

Step 2: The creation of "Google forms" with the information from Step1;

Step 3: The distribution of the "Google forms" to the Groups of moms on social media;

Step 4: The lead of a formative research that helped in defining and perceiving the target population;

Step 5: The creation and dissemination of infographics based on the results of the evaluation of the collected data;

The questionnaire was designed to capture important aspects among the targeted population. The questionnaire had in total forty mixed qualitative and quantitative 
questions, addressing the purposes and concepts of the study. The response rate for the study sample was $100 \%$.

Disseminating the "Google form" questionnaire, there was attached the information page to provide the target population with the necessary information about the current project, purpose and confidentiality of the participant's information. There was also attached the informed consent that was signed by each individual respondent where they stated that the information page has been understood. The ethical considerations were fulfilled by obtaining written consents and maintaining the confidentiality.

An analytical plan was developed that contained procedures and steps used in the data analysis process:

Step 1: Introducing and validating data that were collected through the questionnaire;

Step 2: Describing the sample (in terms of age, gender, ethnicity, residence and etc.) assessing the main variables of interest (parents level of knowledge regarding emergency behavior and parents sharing their knowledge to their children);

Step 3: Computing descriptive statistics in SPSS Statistics 23, such as frequencies, cross-tables, binary and multinomial logistic regression.

\section{Results and Discussions}

The results of the respondent's age are given in Table 1 below:

Table 1.

\begin{tabular}{lcc}
\hline Age & & \\
\hline $\mathrm{N}$ & Valid & 120 \\
Median & Missing & 0 \\
Percentiles & & 37.00 \\
Percentiles & 25 & 32.00 \\
Percentiles & 50 & 37.00 \\
\hline
\end{tabular}

The above table presents the results of the responses provided by the participants. For the age variable it was used a frequency table in order to calculate the percentiles. For finding out the percentiles for this variable there were three values reporting: 25 percentile, 50 percentile and 75 percentile, from which for the 25 percentile, the first quartile indicates that approximatively $25 \%$ of the people are under the age of 32 . For the second quartile, 50 percentile which divides the value exactly in half, shows that there are $50 \%$ below the age of 37 and $50 \%$ above the age of 37 . For the third quartile, the 75 percentile indicates that $25 \%$ of respondents are aged over 40 .

The results of the questionnaire are given below in Table 2: 
Table 2.

\begin{tabular}{|c|c|c|c|c|c|c|c|}
\hline & \multicolumn{2}{|c|}{ Total } & \multicolumn{4}{|c|}{ Parents Readiness } & \multirow[t]{2}{*}{$\begin{array}{c}\mathrm{p}- \\
\text { value }\end{array}$} \\
\hline & $\mathrm{N}$ & $(\%)$ & Ready & $(\%)$ & Not ready & $y \quad(\%)$ & \\
\hline Total & 120 & $(100)$ & 98 & $(81.6)$ & 22 & $(18.3)$ & - \\
\hline Gender & & & & & & & 0.560 \\
\hline Female & 116 & (96.7) & 97 & (96.9) & 21 & (95.5) & \\
\hline Male & 4 & $(3.3)$ & 3 & $(3.1)$ & 1 & $(4.5)$ & \\
\hline Ethnicity & & & & & & & 0.999 \\
\hline Romanian & 119 & $(99.2)$ & 97 & (99) & 22 & $(100)$ & \\
\hline Hungarian & 1 & $(0.8)$ & 1 & $(1)$ & 0 & $(0)$ & \\
\hline Civil status & & & & & & & 0.999 \\
\hline Married & 116 & (96.7) & 94 & (95.9) & 22 & $(100)$ & \\
\hline Unmarried & 3 & $(2.5)$ & 3 & $(3.1)$ & 0 & $(0)$ & \\
\hline Divorced/ Separated & 1 & $(0.8)$ & 1 & $(1)$ & 0 & (0) & \\
\hline Residence & & & & & & & 0.577 \\
\hline Rural & 27 & $(22.5)$ & 21 & $(21.4)$ & 6 & $(27.3)$ & \\
\hline Urban & 93 & $(77.5)$ & 77 & $(78.6)$ & 16 & (72.7) & \\
\hline Education & & & & & & & 0.366 \\
\hline Middle school & 1 & $(0.8)$ & 0 & $(0)$ & 1 & $(4.5)$ & \\
\hline High school & 22 & $(18.3)$ & 19 & $(19.4)$ & 3 & $(13.6)$ & \\
\hline Bachelor & 60 & $(50)$ & 50 & (51.0) & 10 & $(45.5)$ & \\
\hline Master & 36 & $(30)$ & 28 & $(28.6)$ & 8 & $(36.4)$ & \\
\hline PhD & 1 & $(0.8)$ & 1 & $(1)$ & 0 & $(0)$ & \\
\hline Natural disaster knowledge & & & & & & & 0.153 \\
\hline No & 4 & $(3.3)$ & 2 & $(2.0)$ & 2 & $(9.1)$ & \\
\hline Yes & 116 & (96.7) & 96 & (98.0) & 20 & (90.9) & \\
\hline Disaster management knowledge & & & & & & & 0.634 \\
\hline Basic & 87 & $(72.5)$ & 69 & (70.4) & 18 & $(81.8)$ & \\
\hline Intermediary & 27 & $(22.5)$ & 24 & $(24.5)$ & 3 & $(13.6)$ & \\
\hline Advanced & 6 & $(6.0)$ & 5 & $(5.1)$ & 1 & $(4.5)$ & \\
\hline Disaster history & & & & & & & 0.815 \\
\hline No & 56 & $(46.7)$ & 45 & (45.9) & 11 & (50) & \\
\hline Yes & 64 & $(53.3)$ & 53 & $(54.1)$ & 11 & (50) & \\
\hline Courses & & & & & & & 0.999 \\
\hline No & 106 & (88.3) & 86 & $(87.8)$ & 20 & $(90.9)$ & \\
\hline Yes & 14 & $(11.7)$ & 12 & $(12.2)$ & 2 & $(9.1)$ & \\
\hline Knowledge sharing & & & & & & & 0.005 \\
\hline Always & 44 & $(36.7)$ & 41 & $(41.8)$ & 3 & $(13.6)$ & \\
\hline Sometimes & 66 & $(55.0)$ & 52 & $(53.1)$ & 14 & (63.6) & \\
\hline Never & 10 & $(8.3)$ & 5 & $(5.1)$ & 5 & $(22.7)$ & \\
\hline Physical trauma & & & & & & & 0.591 \\
\hline No & 6 & $(5)$ & 6 & $(6.1)$ & 0 & $(0)$ & \\
\hline Yes & 114 & $(95.0)$ & 92 & (93.9) & 22 & $(100)$ & \\
\hline Psychological trauma & & & & & & & 0.999 \\
\hline
\end{tabular}




\begin{tabular}{|c|c|c|c|c|c|}
\hline No & $4 \quad(3.3)$ & 4 & (4.1) & 0 & (0) \\
\hline Yes & 116 (96.7) & 94 & (95.9) & 22 & (100) \\
\hline
\end{tabular}

In order to compare two variables in the second table they were introduced as following: demographic variables compared with parents readiness. This table was used to help in determining the relationship between two variables, to assess the factors and possible predictors of one of the main variable which is knowledge sharing.

In this survey there is no missing data. From a total of 120 participants, 116 reported to be females from which 97 said they are ready to act in case of natural disaster occurrence while 21 said they are not. From the total population there were found 4 respondents to classify as males from which 3 said they are ready to act and 1 said he is not.

The next variable that plays a very important role in this study is the level of education of the participants. The answers for this question were handed out. The first response was checked by one person with the graduated middle school as being the highest level of education he possesses and mentioning that he is not ready to act in case of natural disaster. The second answer provided 22 participants mentioning that they have graduated from high school, from which 19 participants reported to be ready while 3 are not. The third answer marked the biggest number of respondents; 60 participants having graduated with bachelor degree, from which only 10 stated that they are not ready, while 50 are ready. The fourth answer for this question was master level of education for which 36 participants checked the answer, 28 of them being ready to act while 8 were not. The fifth response was answered by one participant who mentioned as being ready to act in case on natural disaster occurrence.

In order to assess the level of knowledge of the targeted population it was asked if they know what a natural disaster is. This variable was also compared to the variable of parents being ready. The results are indicated as following: a population of 116 participants $96.7 \%$ of total population answered with yes they think they know what a natural disaster is, from which 96 stated that they are ready to act while 20 are not.

To better understand the meaning of the previous answers the following question was addressed to the targeted population: what is their level of natural disaster management knowledge. This question was addressed with handed out answers, basic, intermediate and advanced. For each answer the participants were provided with explanation of the terms. Basic knowledge stands for something necessary to know, being aware and familiar of natural disaster presence. Intermediate knowledge was explained as relating or having the knowledge and skills but not yet an expert. Advanced knowledge was defined as having the knowledge and skills and knows how to apply them, also can serve as a hand on knowledge worker. The above table shows the results of the total answers from which the biggest amount of responses were in population as having the basic knowledge for their level of natural disaster management knowledge with 87 respondents from 120, from which 69 are ready to act while 18 are not. The next answer was about having the intermediate knowledge from which a total of 27 participants stated as having this level, 24 as being ready and 3 as not being ready to take action. The last answer for this question was answered by 6 participants as having advanced level of knowledge from which 5 are ready and 1 is not.

The next question was about participant's disaster related history. This question was asked 
for testing the susceptibility of the targeted population. 64 participants out of 120 claimed that they have gone throw a natural disaster in their lifetime from which 53 are ready to take action for occurrence of another natural disaster while 11 are not.

A variable that could influence participants knowledge and attitude are the existing courses and schools providing information in participant's residential area and if they ever took part in one. The above table shows that 106 participants never took part in any courses related to natural disasters from which 86 participants claim that they still are ready to act while 20 are not.

For assessing the number of parents that share their knowledge with their children the next question was asked and provided with possible answers, always, sometime and never. For the first answer 44 participants mention that they always share their knowledge regarding natural disasters with their kids, from which 41 are ready and 3 are not ready to action in case of a natural disaster. For the second answer 66 participants claimed that they sometimes share their knowledge, from which 52 are ready while 14 are not. The last answer was responded by 10 participants that never share their knowledge with their kids from which 5 are ready and 5 are not. From these results it can be deducted that the majority of population shares their knowledge about natural disaster with their children from whom some responded that they are sharing while they do not feel prepared on their own. After receiving these results the next question was to be asked how parents do share their knowledge with their kids while they do not feel ready.

For addressing further questions there was developed a binary logistic regression table Table2, which helped studying more in depth and predict the relationship between independent variables and the dependent variable.

Table 2.

\begin{tabular}{lccc}
\hline & \multicolumn{3}{c}{ Parents readiness } \\
\hline Age & OR & $95 \% \mathrm{Cl}$ & $P$ value \\
Gender & 1.049 & $0.972 \sim 1.132$ & 0.229 \\
Residence & 0.663 & $0.066 \sim 6.694$ & 0.560 \\
Education & 1.375 & $0.479 \sim 3.949$ & 0.577 \\
School & & & 0.366 \\
Undergraduate degree & (Ref) & (Ref) & \\
Graduate degree & 1.053 & $0.294 \sim 3.764$ & \\
Natural disaster knowledge & 0.763 & $0.201 \sim 2.892$ & \\
Courses & 4.800 & $0.638 \sim 36,123$ & 0.153 \\
Disaster history & 1.395 & $0.289 \sim 6.734$ & 0.999 \\
Knowledge sharing & 1.178 & $0.467 \sim 2.971$ & 0.815 \\
Disaster management knowledge & 0.271 & $0.115 \sim 0.635$ & 0.005 \\
Basic & \multicolumn{3}{|c}{0.634} \\
Intermediary & (Ref) & (Ref) & \\
Advanced & 2.087 & $0.564 \sim 7.716$ & \\
\hline
\end{tabular}

In order to better address the problem there was created a hypothesis. $\mathrm{H}_{\mathrm{o}^{-}}$parents who have gone throw a natural disaster are more ready to act in case of occurrence of another 
one than those who had never been throe one.

The odds for parents that are ready increases by 39.5\% with a 95\% confidence interval in those that have gone throw a natural disaster over those who have not. The $P$ value for this hypothesis is 0.999 , which means that we cannot reject the null hypothesis, and we cannot conclude that a significant difference exists.

A multinomial logistic regression table was developed in order to assess the next question. Table 3 was designed to predict the knowledge sharing variable, given parents readiness and natural disaster management knowledge variables.

Table 3.

\begin{tabular}{|c|c|c|c|c|c|}
\hline \multirow{2}{*}{\multicolumn{2}{|c|}{ Knowledge sharing }} & \multicolumn{4}{|c|}{$95 \% \mathrm{Cl}$ for $\operatorname{Exp}(\mathrm{B})$} \\
\hline & & \multirow[t]{2}{*}{$\operatorname{Exp}(B)$} & \multirow[t]{2}{*}{ Lower Bound } & \multirow{2}{*}{ Upper Bound } & \multirow{2}{*}{$\frac{P \text { value }}{0.004}$} \\
\hline Sometimes & Intercept & & & & \\
\hline & Ready parents & 0.253 & 0.062 & 1.028 & 0.055 \\
\hline & Basic disaster knowledge & (Ref) & (Ref) & (Ref) & \\
\hline & Intermediary disaster knowledge & 0.079 & 0.008 & 0.770 & 0.029 \\
\hline & Advanced disaster knowledge & 0.373 & 0.149 & 0.934 & 0.035 \\
\hline \multirow[t]{5}{*}{ Never } & Intercept & & & & 0.151 \\
\hline & Ready parents & 0.070 & 0.011 & 0.435 & 0.004 \\
\hline & Basic disaster knowledge & (Ref) & (Ref) & (Ref) & \\
\hline & Intermediary disaster knowledge & $2.500 \mathrm{E}-9$ & $2.500 \mathrm{E}-9$ & $2.500 \mathrm{E}-9$ & \\
\hline & Advanced disaster knowledge & $6.939 \mathrm{E}-9$ & .000 & & 0.997 \\
\hline
\end{tabular}

The reference category is: Always.

This table concludes with a 95\% confidence interval that the odds for parents who sometimes are sharing their knowledge is 13 times more likely to have intermediate disaster management knowledge and 4 times more likely to be ready in case of natural disaster occurrence than those parents that always share their knowledge and have basic disaster knowledge.

\section{Conclusion and Suggestions}

This study aims to assess self-reported levels of knowledge of parents who have children from 4 to 12 years of age in Romania regarding their behavior in emergency situations. As children are able to better assimilate and apply the information received, this knowledge will allow them to co-operate, adapt and cope with any emergency situation until authorities intervene.

According to the reported results, it can be concluded that natural disaster management knowledge sharing is happening. From Table 3, it can be summarized that preparedness and level of knowledge are big predictors of sharing.

The results of the study will provide a baseline for further interventions, proving that family education can benefit not only human life but can also improve the income by reducing material damage.

Because of a big percentage of parents who stated that they never attended courses and do not have schools providing natural disaster management knowledge in their residential area, a suggestion will be creating schools or provide with human resources that can deliver courses that will increase the knowledge and preparedness of parents to 
successfully deliver it to their children.

\section{Limitations}

No track kept of action like parents that started to fill the questionnaire but didn't finish because of a long survey.

\section{Aknowledgements}

Many thanks to Prof. Razvan M. Chereches for his kind mentorship and valuable insight. Also, many thanks to Babes- Bolyai University for financing this project.

\section{References}

Collins. (2016, June 02). Definition of 'natural catastrophe' [Online]. Retrieved from: https://www.collinsdictionary.com/dictionary/english/natural-catastrophe

Gavriletea, M.D. (2017, May 08). Catastrophe risk management in Romania and Transylvania' specifics. Issues for national and local administrations [Online]. Retrieved from: http://www.tandfonline.com/doi/pdf/10.1080/1331677X.2017.1314817?needAccess=true

Education. (2010, Julie 20). Families and Early Childhood [Online]. Retrieved from: https://www.education.com/reference/article/families-early-childhood/

Fagarasan, A., Szalankiewicz, D., \&amp; Ekengren, M. (2013, June). Analisys of Civil Security Systems in Europe [Online]. Retrieved from: http://anvil-project.net/wpcontent/uploads/2013/12 /Romania_v1.0.pdf.

Newsroom. (2011, October 12). Romania has unique exposure to natural disasters [Online]. Retrieved from: http://www.business-review.eu/news/romania-has-unique-exposure-to-natural-disasters-125422292

Centru national de informatii biotehnologice. (2011, February 28). Effects of first aid training in the kindergarten - a pilot study [Online]. Retrieved from: https://www.ncbi.nlm.nih.gov/pmc/articles /PMC3060136/

The Japan Times. (2015, September). Proper preparation for disasters [Online]. Retrieved from: https://www.japantimes.co.jp/opinion/2015/09/02/editorials/proper-preparationdisasters/\#.WecZ3VuCzIV

Kids Web Japan. (2007, April 23). Schools [Online]. Retrieved from: http://webjapan.org/kidsweb/explore/schools/q6.html

Beville, R. (2011, September 13). Coping with Disaster and Preparing for the Future: An On-the-Ground View of Japan's Earthquake Recovery Effort [Online]. Retrieved from: https://www.brookings.edu/opinions/coping-with-disaster-and-preparing-for-the-future-an-onthe-ground-view-of-japans-earthquake-recovery-effort/

Haque, Ubydul et al., (2016, May 07). Fatal landslides in Europe [Online]. Retrieved from: https://link.springer.com/article/10.1007/s10346-016-0689-3

McGrath, Matt. (2017, August 10). Climate change has shifted the timing of European Floods [Online]. Retrieved from: http://www.bbc.com/news/science-environment-40889934

Departamentul de educatie al Californiei. (2000). Ages and Stages of Development [Online]. Retrieved from: https://www.cde.ca.gov/sp/cd/re/caqdevelopment.asp

Tuladhar, Gangalal. (2013, June 03). Knowledge of disaster risk reduction among school students in Nepal [Online]. Retrieved from: http://www.tandfonline.com/doi/full/10.1080/19475705.2013.809556 